\title{
Residues: Rethinking Chemical Environments
}

\author{
SORAYA BOUDIA \\ UNIVERSITÉ PARIS DESCARTES \\ ANgela N. H. CREAGeR \\ PRINCETON UNIVERSITY \\ SCOTT FRICKEL \\ BROWN UNIVERSITY \\ EMMANUEL HENRY \\ UNIVERSITÉ PARIS - DAUPHINE, PSL UNIVERSITY \\ NATHALIE JAS \\ INSTITUT NATIONAL DE LA RECHERCHE AGRONOMIQUE \\ CARSTEN REINHARDT ${ }^{\circ}$ \\ UNIVERSITY OF BIELEFELD \\ JODY A. ROBERTS \\ SCIENCE HISTORY INSTITUTE
}

\begin{abstract}
This essay offers a new approach for conceptualizing the environmental impact of chemicals production, consumption, disposal, and regulation. Environmental protection regimes tend to be highly segmented according to place, media, substance, and effect. Existing scholarship often reflects this same segmentation, by focusing on a locality,

. Soraya Boudia, Email: soraya.boudia@parisdescartes.fr

2 Angela N. H. Creager, Email: creager@princeton.edu

${ }_{3}^{3}$ Scott Frickel, Email: scott_frickel@brown.edu

‘ Emmanuel Henry, Email: emmanuel.henry@dauphine.fr

${ }_{5}^{5}$ Nathalie Jas, Email: nathalie.jas@inra.fr

•Carsten Reinhardt, Email: carsten.reinhardt@uni-bielefeld.de

Jody A. Roberts, Email: jroberts@sciencehistory.org

Copyright ( 2018 (Soraya Boudia, Angela N. H. Creager, Scott Frickel, Emmanuel Henry, Nathalie Jas, Carsten Reinhardt, Jody A. Roberts) Licensed under the Creative Commons Attribution Non-commercial No Derivatives (by-nc-nd). Available at estsjournal.org.
\end{abstract}


specific chemical, social movement, or regulatory body. In turn, as new environmental measures are introduced to deal with pollution and toxicity, they tend to focus on controlling future effects rather than dealing with the accumulated contamination from past industrial activity and waste. In chemical substances we encounter phenomena that are at the same time voluminous and miniscule, regulated yet unruly. Inspired by recent work on materiality and infrastructures, we focus on the concept of residues as both material and political entities. Following residues, we argue, helps us see how the past has been built into our chemical environments and regulatory systems, and why contaminants seem to always evade control.

\section{Keywords}

chemicals; industry; residue; environmental health; regulation; environmental justice

\section{I.}

Environmental health, politics, and regulation have become important topics to STS scholars, in part because of the urgency, complexity, and scale of contemporary environmental problems. Research has nucleated around several key topic areas: the science and medicine of exposure and chemical safety; the role of technical experts in government decision making; actions by industry to forestall regulation by magnifying scientific uncertainty; and the mobilization of environmental justice movements that understand risk to be stratified by race and class, to name a few (e.g., Boudia \& Jas 2014; Brown 2007; Cranor 1993; Jasanoff 1990; Krimsky 2000; Langston 2010; Markowitz \& Rosner 2002; Pellow 2007; Proctor 1995; Sellers 1997; Shostak 2013). For each of these issues, the relevant environmental problems implicate chemical manufacturing and pollution. Since the publication of Controlling Chemicals by Ronald Brickman, Sheila Jasanoff, and Thomas Ilgen (1985), scholars who have squarely addressed the industry and its manifold environmental consequences have generally focused on a polluted locality (a mining or fenceline community, or a building), a type of toxin (lead, PCBs, or Bisphenol-A), a type of victim (consumer, worker, resident, ecosystem), or a regulatory regime (e.g., Allen 2003; Boullier 2016; Fortun 2001; Henry 2007; Murphy 2006; Ross and Amter 2010; Vogel 2013).s This literature has been exceedingly valuable in illustrating the scope and recalcitrance of environmental problems related to the chemical industry, but reflects the same kind of segmentation that bedevils environmental regulatory systems. Recent developments in STS, such as the scholarly attention to materiality and infrastructures, suggest promising avenues for reconsidering the production and control of chemicals (Bennet 2010; Bowker \& Starr 1999; Law 2010; Slota \& Bowker 2017). We are exploring how these approaches might be exploited to theorize from chemical domains rather than applying theory to chemical cases.

s There is also scholarship on chemicals regulation in various national contexts, which we will not attempt to cite here, including work by sociologists, political scientists, legal scholars, and environmental and labor historians. For examples of work on transnational regulation of chemicals, see note 10 . 
In this Considering Concepts essay, we invite collective rethinking about chemical environments, focusing on the notion of a residue. Residues need not be bound to a place, a substance, an effect, or a regulation, but instead afford us a multivalent conceptual tool for dealing with the dynamic complexities of chemical environments, both concrete and abstract. Moreover, by offering a reimagined vocabulary and program for research, we hope to nudge academic and public discussion of chemical production as it relates to regulation and environmental health beyond the cul-de-sacs of exasperation, complacency, and despair.

\section{II.}

Residue is an old idea. It derives from the Latin, residuum, meaning "something remaining." The meaning has not changed much over the centuries. A contemporary definition describes residue as "a small amount of something that remains after the main part has gone or been taken or used" (Oxford Dictionaries online). In law, this something refers to what remains of an estate after taxes, debts, and bequests are paid. And in chemistry, residue refers to "that which remains after a process of combustion, evaporation, digestion, etc.; a deposit or sediment; a waste or residual product" (Oxford English Dictionary online). Consonant with aspects of all of these definitions, the residues we wish to describe are at once by-products of extractive and industrial technology, history, and organization and also catalysts escaped from the lab or the landfill or the mine and urging into existence new biological, chemical, geological and sociotechnical worlds. We think residue is a concept that can capture the multi-faceted nature of chemicals.

For STS scholars, the idea of residue holds two distinct and novel attractions. One attraction is the promise of new method. Like biological tracers, we can use residues to chart the chemical dispersions and transformations set into motion by industrialization, often disclosing unanticipated environmental and social costs of living on what is now a "synthetic planet" (Casper 2003; Creager 2013). Residues are transgressive. They disobey boundaries, appear where they shouldn't appear, alter environments, and enter communities and bodies without permission. ${ }^{10}$ Following them around, rooting them out, holding them up to the light, allows a different world to come into view, a world we cannot see so clearly if we begin our exploration with the economics of chemical production or the legal studies of chemical regulation or the chemical politics of sick communities. The other attraction that residues hold for us is theoretical. In transposing a key category from its everyday and scientific usage, we are engaging in what Henry Cowles has called "endogenous analytics," peering closely at our chemical subjects for clues as to how to understand them anew (Cowles 2014: 15; Cowles 2016).

- Recently (while we were preparing this piece), Gabrielle Hecht (2018) published an essay using the same concept, as seen through governance of contaminants from mining. Our approaches are consonant but not identical.

${ }_{10}$ The "transboundary" nature of chemical pollution made it an issue of international negotiation and regulation by the 1970s: Eckley (2000); Eriksson, Gilek, \& Ruden (2010); Long (2000); Pallemarts (2003); Rothschild (2014); Rothschild (forthcoming); Selin (2010). 
We find five properties of residue especially interesting and use diverse empirical examples to tease apart the theoretical significance of each one. These five properties can be distinguished analytically but they are also closely related. Politics runs through all of these aspects of residues, a consistent point of their interconnection. This is our lone caveat and starting premise.

First, the term "residue" is marked from the outset by a kind of irreversibility. "Something remaining" implies past action. Residues are the results or outcome of some already concluded process. They are leftovers. Remnants. In this sense, residues cannot escape their history and provide clues for reconstructing the chemical past. This is equally true of chemical products which are not human-made and those that are synthetic. Humans come into contact with lead, a natural but highly toxic metal, because it has been extracted for industrial purposes and permanently redistributed across the environment." PCBs, by contrast, did not exist before chemists synthesized them. During the middle decades of the twentieth century, as the electrical infrastructure for the growing industrial economies was built, PCBs entered landscapes, workplaces, and households, in air conditioners, fluorescent light fixtures, refrigerators, television sets, and electrical transformers. Their insolubility in water and resistance to corrosion led PCBs to be used in carbonless copy paper, paints, sealants, ironing board covers, and plastic bottles. Because of their very slow degradation (physically or biologically), PCBs will linger in the environment indefinitely, though they were banned decades ago, and their fat solubility means that these toxic residues continue to bio-accumulate in food webs (Spears 2014: 1-4; US Senate, Committee on Environment and Public Works, Subcommittee on Superfund and Environmental Oversight 1988: ch. 2). Michel Serres observes that "pollution comes from measurable residues of the work and transformations related to energy, but fundamentally it emanates from our will to appropriate, our desire to conquer and expand the space of our properties" (Serres 2011: 42). Serres' work reminds us that the irreversibility of residues emanates not only from the molecular nature of the chemical substances, but also from the politics of production and regulation-of decisions to create toxicants as well as decisions to not clean up the leftovers (Reinhardt 2010). As irreversible objects, these residues-both material and political--can't simply be undone, undermining the idea that there is a "pre-" era to which we can return, even if politically and economically powerful actors want it so (Shotwell 2016; Tsing 2015). As Jens Beckert has argued, capitalism tends to restrict attention to future possibilities (Beckert 2016). Residues remind us that the past cannot be ignored.

Second, residues are material objects, though often neglected or treated as immaterial. Because residues can be thin, faint, negligible, and difficult to see, they are also easy to ignore, which can be politically useful. Residues' there-but-not-there quality belies not only a material existence but, often, their actual volume. For example, in mining the residues generated from extraction and refinement often far exceed the final product. In this way, even as mountains of sometimes-toxic "tailings" remain invisible to ultimate consumers, they tend to pile up among

"Geochemist Clair Patterson presented compelling evidence in 1965 that lead exposure was directly related to industrialization and warned of the public health hazards of viewing it as a natural part of the environment. See Warren (2000); Markowitz \& Rosner (2013). 
socio-economically disadvantaged populations and already degraded ecosystems (McNeill \& Vrtis 2017). And even when the physical volumes of residues are miniscule they have substantive, empirical presence and political consequence. For example, toxicity dose-response curves are not always linear; sometimes a little bit of a toxin can cause disproportionate harm (Khetan 2014). So can cumulative effects. We interact with residues all the time and chronic exposure to a little poison every day can add up to a lot of poison over the course of a human lifetime or--when we are dealing with heritable mutations--generations (Chen and McKone 2001). The geographic dispersion of residues can also make an important difference because a little bit everywhere adds up to a lot. At the height of the Roman Empire, coinage forged from Iberian smelters produced enough fugitive lead to coat the globe, raising the planet's atmospheric lead to levels that are still measurable today (Tainter 2000). In each of these examples, our mistake, and sometimes our political folly, lies in believing that a little bit of something is the same as none at all.

Third, residues are slippery. They have a way of escaping modern production and regulatory systems and are often hiding in plain sight. Our standard surveillance systems miss residues when we don't look in the right place or we don't look for the right thing. Sometimes, we simply don't look at all. We know about pesticides on crops, but we miss the pesticides that drift over farm workers and their families (Bohme 2014; Daniel 2005; Harrison 2011). We know how to react to the dramatic oil spills that grab headlines and despoil coastlines, but we are stymied by the slow drip, drip, drip of crescive oil disasters-in-the-making (Beamish 2002). And even when we know what to look for and where to find it, some residues still slip away. Silver nanoparticles used in common consumer products like shampoos and conditioners wash down the shower drain, ending up in water treatment facilities that tend to do a good job of pulling nanomaterials out of waste water. But then the silver particles are incorporated into the solid waste stream, much of which is recycled as organic nutrients onto agricultural fields. From there, rain and wind wash nano-silver off the fields and back into streams, despite our best efforts to curtail its travels (Dale, Casman, Lowry, Lead, Viparelli, \& Baalousha 2015). Nanoparticles are not unique in their slick mobility. Exhibit B is surely micro-plastics, now known to lurk in fresh seafood and quite possibly in our kitchen salts, honey jars, and beer (EFSA Panel on Contaminants in the Food Chain 2016). ${ }^{12}$ As a growing list of so-called "emerging" contaminants attests, the politics of residues are slippery too. From organochlorines to phenols to neonicotinoids to per- and polyfluoroalkyl substances, knowledge of these chemicals' whereabouts and effects seems always to arrive too late for preventive policy.

Fourth, residues are unruly, behaving and transforming unpredictably. Once at large, they interact with each other and the environment in complicated ways. Sometimes, of course, these interactions helpfully eradicate residues. Many synthetic materials break down and are completely taken up into the ecosystems, contributing to the biomass and nutrient cycles that

${ }_{12}$ Beyond fish, data on microplastic occurrence in food are limited. Confirmation of early studies reporting positive results are hampered by the lack of regulatory limits and standardized methodologies. On microplastics in salt, see Karami, Golieskardi, Choo, Larat, Galloway, \& Salamatinia (2017); on honey, see Liebezeit, G. and E. Liebezeit (2013); on beer, see Liebezeit, G. and E. Liebezeit (2014). 
perpetuate diverse life forms. But not all residues rejoin the environment as ecologically innocuous participants, and their persistence provides a kind of chemical record of industrialization, innovation, and consumer choice. Some residues that are not harmful outside human bodies are metabolized into toxic substances once inside them. Moreover, residues team up. Chemical emissions interact with each other and with substances that are in the soil and air, producing pollutants we had not planned-or planned for. ${ }^{13}$ To take familiar examples, ozone and acid rain are both formed by chemical reactions of different kinds of industrial pollutants with the environment (sunlight in the first case and water in the second). Residual antibiotics from agriculture and aquaculture that enter the environment as waste contribute to the prevalent problem of resistance; it turns out that heavy metals, frequently a co-contaminant of antibiotics, further select for antibiotic resistance (Seller \& Berendonk 2012). These interactions pose problems for environmental protection laws, which regulate exposures substance-by-substance, task-by-task, and medium-by-medium. This kind of hyper-segmentation in the law does not correspond to a three-dimensional world of mixtures and mobility, in which industrial chemicals and organisms interact in air, soil, and water to generate unexpected entities, environments, and risks.

Fifth, residue is primarily valued for the work it creates, less so for the work it accomplishes. It has an odd sort of negative identity: matter that is not supposed to matter. To call something a residue means that its useful life is effectively over; that is has aged, moved on, or is otherwise to be disregarded. Residue can become costly in its cleanup, however. When they are labeled as waste, residues require further work or energy to clean up, dissolve, remove. It is the unwantedness of residue, and the negative attention it inspires, that can make it incredibly expensive. To take a "crude" example, the oil lost to British Petroleum, LLC, when it gushed uncontrolled from the Deepwater Horizon oil platform in the Gulf of Mexico in 2010, was then valued at about $\$ 250$ million (Crooks 2016)." The cost to responsible parties and US taxpayers for stopping the leak and cleaning up the spilled oil is estimated to be $\$ 14$ billion. ${ }^{5}$ But when residues are not identified as waste, they can lurk in invisibility. They are there, but not there, like the island-sized patches of plastic debris littering the oceans." In this way, the bureaucratic act of labeling chemicals--as wanted/unwanted, important/unimportant-attaches residues to geopolitics. Labeling practices vary from country to country so that what is a residue in one country or at one time is a useful chemical product in another, creating discontinuities in international policy. For example, asbestos is now considered a residue in the few countries that have banned it while it continues to be used as a building material in many other countries. Plastic bags are increasingly seen as objects to be banned from cities when they were still considered useful (if not indispensable) just a few years ago. In this way, bureaucratizing

${ }_{13}$ These are called secondary pollutants.

${ }_{14}$ Calculated for inflation at August 2016 dollars.

https:/ / inflationdata.com/Inflation/Inflation_Rate/Historical_Oil_Prices_Table.asp

${ }_{15}$ This figure does not include costs of civil penalties, environmental damages, criminal fines, and compensation to businesses and individuals. Crooks (2016).

${ }_{16}$ Scientists have identified five such massive patches in the world's oceans (Mosbergen 2017). 
chemicals can amount to an uneven vanishing act, serving as blinders on which environmental left-overs we notice, and which we fail to perceive; which we pay to clean up and which we leave alone.

\section{III.}

The five social properties of residues are interesting in themselves, but only provide the starting point for our collaborative effort. They help us reimagine how chemical matter matters and they bring into better focus an emerging residues-oriented research program organized around three universal processes, namely legacy, accretion, and apprehension. We have found these three processes to be helpful in integrating empirical cases from our different STS fields of history, sociology, and political science." While these three themes gather our insights in productive ways, they do not exhaust the possibilities of the analytic category of residue. Rather, we sketch out our particular research agenda to invite other STS scholars to consider how residues might inhabit, or even illumine, their own scholarly engagement with the environment.

To begin, residues exhibit the path-dependence and persistence of chemical contaminants, as matter out of time. More so than kindred concepts like temporality or history, legacy gives emphasis to the residual. Residues are what remain behind and remind us that with chemicals and other residues of the industrial age, the past is always present. The prior activities of human societies, whether two thousand years ago or two days ago, generate chemical residues that end up somewhere else, whether in water, air, on land, or in bodies. As the extensive contamination of the oceans with microplastic debris illustrates, we are swimming in the waste of the petrochemical era even as the production stream of disposables continues. The legacies of consumer chemicals involve not only material remains but also regulatory systems, which usually change by addition or modification, dragging administrative organizations and legal precedents interminably forward. Itself a by-product of jurisdictional limits and court challenges, regulation is an integral part of the production system from which residues have issued.

Additionally, to take a cue from Mary Douglas, residues represent matter out of place (Douglas 1966). Residues travel but also assemble, through processes of accretion. Consider how displaced residues from industrial activities accumulate, over time, as property owners and land uses change, and the role of regulatory rules in facilitating the dual accumulation of capital and hazardous waste (Frickel and Elliott 2018). Or the conundrums in dealing with electronic waste, for which recycling is a limited way to deal with the environmental and health impacts of decades of rare earth extraction, production, and disposal. Accretion shows us how, literally and figuratively, residue covers ground.

Residue can also be matter out of reason. We will signal this aspect as apprehension, playing on its double meaning: understanding and worries (Shapiro, Zakariya, \& Roberts 2017). Apprehension refers to human capacities to perceive and make sense of residues as part of our

${ }^{1}$ We are currently at work on a book manuscript which more fully develops these themes with a variety of examples from our individual and collective research. 
physical environment. What we know, and what we don't know, and the ways in which systems of regulatory knowledge-making also produce ignorance, are highlighted as we consider apprehension (Frickel \& Edwards 2014). It also refers to the emotional and moral character of residues as invoking danger. The material reality of residue challenges our systems of reasonmaking, especially those involving markets, science, and politics.

\section{IV.}

All told, we find the idea of residue exciting because it helps us reframe and reconceptualize chemical environments in STS. One final example is how it refracts the Anthropocene, a topic that has taken environmental studies by storm (Crutzen \& Stoermer 2000; Crutzen 2002)." In one sense (a material sense), residues are the Anthropocene--incontrovertible evidence of human activity that has become sedimented into the planet's terrestrial record. Residues are the chemical and elemental signals that physical geologists are using to identify a new epoch, mark its origins in time and space, and trace out the stratigraphic consequences of human history for Earth history. In another, more discursive sense, residues subvert a popular narrative about the environmental costs of industrialization, which has been tethered to the combustion of carbon and atmospheric climate change. Burning carbon creates residue, of course. But this framing misses the other side of the carbon coin: Oil and gas are the feedstocks for chemical industry, which synthesizes a massive variety of compounds used in every sector of the economy. Residues helps us see the Anthropocene as combustion and synthesis of carbon-containing compounds, as well as the industrial manipulations of dozens of other chemical elements. These material transformations are rearranging not only atmospheric and ocean chemistry, but biology as well, altering the course of evolution, including human evolution (Frickel 2004).

As this rendering of the Anthropocene illustrates, residue offers a way to reckon with environmental change and regulation in terms of its materiality and irreversibility. It enables us to draw on environmental science while recognizing its limitations, as well as to employ our critical perspective as social scientists. In tracking residues, we necessarily confront the present/past nature of chemical contaminants, the unavoidable issues of scale, and the conundrum of voluminous yet inadequate data. We see residues, presented here as a set of material-social properties enmeshed with processes of legacy, accretion and apprehension, as building capacity within STS to catalyze theory generated from chemical domains and so reimagine and remake our environments.

\footnotetext{
is As proposed by Crutzen and Stoermer (2000), the Anthropocene refers to a period of human-induced changes to Earth's biogeochemical systems. It is meant to replace the Holocene as the current geological era. Crutzen and Stoermer suggested that the late 18th century provided a useful starting date consonant with James Watt's improvement of the steam engine in 1784. Among geologists, debate continues about when the Anthropocene began. Some argue for 10,000 years ago with the rise of large-scale agriculture; others argue for 1950, with the commencement of nuclear testing.
} 


\section{Author Biography}

Soraya Boudia is Professor of Sociology at the Université Paris Descartes. Working at the intersection of science studies and environmental studies, her scholarship examines the relationships between science, politics and economy. Her current research is on the politics of hazardous waste.

\section{Author Biography}

Angela N. H. Creager is the Thomas M. Siebel Professor in the History of Science at Princeton University. Research for her most recent book, Life Atomic: A History of Radioisotopes in Science and Medicine (University of Chicago Press, 2013), sparked her interest in environmental contamination and regulation.

\section{Author Biography}

Scott Frickel is Professor of Sociology and Environment and Society at Brown University and Community Engagement Core Leader for the Brown Superfund Research Program. Interested in how nature, knowledge, and politics combine, his latest book, with James R. Elliott, is a comparative study of urban socioenvironmental change titled Sites Unseen: Uncovering Hidden Hazards in American Cities (Russell Sage Foundation and the ASA Rose Series in Sociology, 2018).

\section{Author Biography}

Emmanuel Henry is Professor of Sociology at Université Paris-Dauphine, PSL University. He is currently working on the links between scientific knowledge (and ignorance), expertise, and public policy, mostly in the fields of occupational and environmental health. He recently published Ignorance scientifique et inaction publique (Paris, Presses de Sciences Po, 2017).

\section{Author Biography}

Nathalie Jas is an STS scholar and senior researcher at the French Institute for Agricultural Research (INRA), in Paris. Her current research interest lies in the socio-history of the governance of hazardous chemicals in the 20th and 21st centuries, with a particular interest in pesticidesrelated issues.

\section{Author Biography}

Carsten Reinhardt is professor of historical studies of science at the University of Bielefeld, Germany. His research fields are the history of chemistry, industrial research, scientific instrumentation, and expert knowledge and regulation in their interaction with politics. 


\section{Author Biography}

Jody A. Roberts is director of the institute for research at the Science History Institute, in Philadelphia. The Institute's research focuses on the development of methods and tools that experiment with the unique capabilities of the science humanities to contribute to a more inclusive conversation about the place of science and technology in our lives. He continues to work in the area of the history of sustainability and environmental regulation and opening up narrative spaces that imagine sustainable futures.

\section{References}

Allen, Barbara L. 2003. Uneasy Alchemy: Citizens and Experts in Louisiana's Chemical Corridor Disputes. Cambridge, MA: MIT Press.

Beamish, Thomas D. 2002. Silent Spill: The Organization of an Industrial Crisis. Cambridge, MA: MIT Press.

Beckert, Jens. 2016. Imagined Futures: Fictional Expectations and Capitalist Dynamics. Cambridge, MA: Harvard University Press.

Bennet, Jane. 2010. Vibrant Matter: A Political Ecology of Things. Durham, NC: Duke University Press.

Bohme, Susanna Rankin. 2014. Toxic Injustice. A Transnational History of Exposure and Struggle. Berkeley, CA: University of California Press.

Boudia, Soraya, and Nathaie Jas (eds). 2014. Powerless Science? Science and Politics in a Toxic World. Oxford: Beghahn Books.

Boullier, Henri. 2016. Autoriser pour interdire. La fabrique des savoirs sur les molécules et leurs risques dans le règlement européen $R E A C H$. PhD Thesis, Université Paris-Est.

Bowker, Geoffrey C., and Susan Leigh Star. 1999. Sorting Things Out: Classification and Its Consequences. Cambridge, MA: MIT Press.

Brickman, Ronald, Sheila Jasanoff, and Thomas Ilgen. 1985. Controlling Chemicals: The Politics of Regulation in Europe and the United States. Ithaca, NY: Cornell University Press.

Brown, Phil. 2007. Toxic Exposures: Contested Illnesses and the Environmental Health Movement. New York: Columbia University Press.

Casper, Monica J. (ed). 2003. Synthetic Planet: Chemical Politics and the Hazards of Modern Life. New York: Routledge.

Chen, Wan-chin G., and Thomas E. McKone. 2001. "Chronic Health Risks from Aggregate Exposures to Ionizing Radiation and Chemicals: Scientific Basis for an Assessment Framework." Risk Analysis 21: 25-42.

Cowles, Henry M. A Method Only: The Evolving Meaning of Science in the United States, 1830-1910. PhD dissertation, Princeton University, 2015.

Cowles, Henry M. 2016. Review of Angela N. H. Creager, Life Atomic: A History of Radioisotopes in Science and Medicine. Medical History 60: 563-565. 
Cranor, Carl F. 1993. Regulating Toxic Substances: A Philosophy of Science and the Law. New York: Oxford University Press.

Creager, Angela N. H. 2013. Life Atomic: A History of Radioisotopes in Science and Medicine. Chicago: University of Chicago Press.

Crooks, Ed. 2016. "BP Draws Line Under Gulf Spill Costs." Financial Times, July 14. https: / / www.ft.com/ content/ ff2d8bcc-49e9-11e6-8d68-72e9211e86ab

Crutzen, Paul J., and Eugene F. Stoermer. 2000. "The 'Anthropocene.'” IGBP Global Change Newsletter 41: 17-18.

Crutzen, Paul J. 2002. "Geology of Mankind." Nature 415: 23. DOI: https:// doi.org/10.1038/415023a.

Dale, Amy L., Elizabeth A. Casman, Gregory V. Lowry, Jamie R. Lead, Enrica Viparelli, and Mohammed Baalousha. 2015. "Modeling Nanomaterial Environmental Fate in Aquatic Systems." Environmental Science and Technology 49: 2587-2593.

Daniel, Pete. 2005. Toxic Drift: Pesticides and Health in the Post-World War II South. Baton Rouge, LA: Louisiana State University Press.

Douglas, Mary. 1966. Purity and Danger: An Analysis of Concepts of Pollution and Taboo. New York: Praeger.

Eckley, Noelle. 1999. "Drawing Lessons about Science-Policy Institutions: Persistent Organic Polluants (POP) under the LRTAP Convention." Belfer Center for Science \& International Affairs Discussion Paper, Harvard University, Report n E-99-11.

EFSA Panel on Contaminants in the Food Chain. 2016. "Presence of Microplastics and Nanoplastics in Food, with Particular Focus on Seafood." EFSA Journal 14(6): 4501 https: / / doi.org/10.2903/j.efsa.2016.4501

Eriksson, Johan, Mickael Gilek, and Christina Ruden (eds). 2010. Regulating Chemical Risks: European and Global Challenges. Dordrecht: Springer.

Fortun, Kim. 2001. Advocacy After Bhopal: Environmentalism, Disaster, New Global Orders. Chicago: University of Chicago Press.

Frickel, Scott. 2004. Chemical Consequences: Environmental Mutagens, Scientist Activism, and the Rise of Genetic Toxicology. New Brunswick, NJ: Rutgers University Press.

Frickel, Scott and Michele Edwards. 2014. “Untangling Ignorance in Environmental Risk Assessment." In Powerless Science? Science and Politics in a Toxic World, edited by Soraya Boudia and Nathalie Jas. Oxford: Berghahn Books, 215-233.

Frickel, Scott and James R. Elliott. 2018. Sites Unseen: Uncovering Hidden Hazards in American Cities. New York: Russell Sage Foundation and the ASA Rose Series in Sociology.

Harrison, Jill Lindsey. 2011. Pesticide Drift and the Pursuit of Environmental Justice. Cambridge, MA: MIT Press.

Hecht, Gabrielle. 2018. "Residue." Somatosphere: Science, Medicine, and Anthropology, January 8. Accessed 16 April 2018. http:/ / somatosphere.net/ ?p=14079.

Henry, Emmanuel. 2007. Amiante: un scandale improbable: Sociologie d'un problème public. Rennes: Presses Universitaires de Rennes. 
Jasanoff, Sheila. 1990. The Fifth Branch: Science Advisers as Policymakers. Cambridge, MA: Harvard University Press, 1990.

Karami, Ali, Abolfazl Golieskardi, Cheng Keong Choo, Vincent Larat, Tamara S. Galloway, \& Babak Salamatinia. 2017. "The Presence of Microplastics in Commercial Salts from Different Countries." Scientific Reports 7: 46173. doi:10.1038/srep46173

Khetan, Sushil K. 2014. Endocrine Disruptors in the Environment. Hoboken, NJ: Wiley.

Krimsky, Sheldon. 2000. Hormonal Chaos: The Scientific and Social Origins of the Environmental Endocrine Hypothesis. New York: New York University Press.

Langston, Nancy. 2010. Toxic Bodies: Hormone Disruptors and the Legacy of DES. New Haven: Yale University Press.

Law, John. 2010. "The Materials of STS." In The Oxford Handbook of Material Culture Studies, edited by Dan Hicks and Mary C. Beaudry. London and New York: Oxford University Press, 171-186. DOI:10.1093/oxfordhb/9780199218714.013.0006

Liebezeit, Gerhard, and Elisabeth Liebezeit. 2013. "Non-Pollen Particulates in Honey and Sugar." Food Additives and Contaminants. Part A, Chemistry, Analysis, Control, Exposure and Risk Assessment, 30, 2136-2140.

Liebezeit, Gerhard, and Elisabeth Liebezeit. 2014. "Synthetic Particles as Contaminants in German Beers." Food Additives and Contaminants. Part A, Chemistry, Analysis, Control, Exposure and Risk Assessment, 31, 1574-1578.

Long, Bill L. 2000. International Environmental Issues and the OECD, 1950-2000: An Historical Perspective. Paris: Organisation for Economic Cooperation and Development.

Markowitz, Gerald, and David Rosner. 2002. Deceit and Denial: The Deadly Politics of Industrial Pollution. Berkeley, CA: University of California Press

Markowitz, Gerald, and David Rosner. 2013. Lead Wars: The Politics of Science and the Fate of America's Children. Berkeley, CA: University of California Press.

McNeill, John R., and George Vrtis (eds). 2017. Mining North America: An Environmental History since 1522. Berkeley, CA: University of California Press.

Mosbergen, Dominique. 2017. "New Plastic Garbage Patch Found in the South Pacific Could Be '1.5 Times Larger Than Texas.'” Huffington Post, 2 Aug. https: / / www.huffingtonpost.com/entry/ south-pacific-garbagepatch_us_59818f92e4b0353fbb3387ac

Murphy, Michele. 2006. Sick Building Syndrome and the Problem of Uncertainty: Environmental Politics, Technoscience, and Women Workers. Durham, NC: Duke University Press.

Pallemaerts, Marc. 2003. Toxics and Transnational Law: International and European Regulation of Toxic Substances as Legal Symbolism. Oxford: Hart Publishing.

Pellow, David. 2007. Resisting Global Toxics: Transnational Movements for Environmental Justice. Cambridge, MA: MIT Press.

Proctor, Robert N. 1995. Cancer Wars: How Politics Shapes What We Know and Don't Know about Cancer. New York: Basic Books.

Reinhardt, Carsten. 2010. "Regulierungswissen und Regulierungskonzepte." Berichte zur Wissenschaftsgeschichte 33: 351-364. 
Ross, Benjamin, and Steven Amter. 2010. The Polluters: The Making of Our Chemically Altered Environment. Oxford: Oxford University Press.

Rothschild, Rachel. 2014. "Burning Rain: The Long-range Transboundary Air Pollution Project." In Toxic Airs: Chemical and Environmental Histories of the Atmosphere, edited by James Rodger Fleming and Ann Johnson. Pittsburgh, PA: University of Pittsburgh Press, 181-207.

Rothschild, Rachel. Forthcoming. Poisonous Skies: Acid Rain and the Globalization of Pollution. Chicago: University of Chicago Press.

Selin, Henrik. 2010. Global Governance of Hazardous Chemicals: Challenges of Multilevel Management. Cambridge, MA: The MIT Press.

Seller, Claudia, and Thomas U. Berendonk. 2012. "Heavy-Metal Driven Co-Selection of Antibiotic Resistance in Soil and Water Bodies Impacted by Agriculture and Aquaculture." Frontiers in Microbiology 3: article 399.

Sellers, Christopher C. 1997. Hazards of the Job: From Industrial Disease to Environmental Health Science. Chapel Hill, NC: University of North Carolina Press.

Serres, Michel. 2011. Malfeasance: Appropriation through Pollution? trans. Anne-Marie FeenbergDibon. Stanford, CA: Stanford University Press.

Shapiro, Nicholas, Nasser Zakariya, and Jody Roberts. 2017. "A Wary Alliance. From Enumerating the Environment to Inviting Apprehension." Engaging Science, Technology, and Society, 3: 575-602.

Shostak, Sara. 2013. Exposed Science: Genes, the Environment, and the Politics of Population Health. Berkeley, CA: University of California Press.

Shotwell, Alexis. 2016. Against Purity: Living Ethically in Compromised Times. Minneapolis, MN: University of Minnesota Press.

Slota, Stephen C., and Geoffrey C. Bowker. 2017. "How Infrastructures Matter." In The Handbook of Science and Technology Studies, 4" edition, edited by Ulrike Felt, Rayvon Fouché, Clark A. Miller, and Laurel Smith-Doerr. Cambridge, MA: MIT Press, 529-554.

Spears, Ellen Griffith. 2014. Baptized in PCBs: Race, Pollution, and Justice in an All-American Town. Chapel Hill, NC: University of North Carolina Press.

Tainter, Joseph A. 2000. "Global Change, History, and Sustainability." In The Way the Wind Blows: Climate, History, and Human Action, edited by Roderick J. McIntosh, Joseph A. Tainter, and Susan Keech McIntosh. New York: Columbia University Press, 331356.

Tsing, Anna Lowenhaupt. 2015. The Mushroom at the End of the World: On the Possibility of Life in Capitalist Ruins. Princeton, NJ: Princeton University Press.

US Senate, Committee on Environment and Public Works, Subcommittee on Superfund and Environmental Oversight. 1988. Implementation of the Toxic Substances Control Act, the PCB Rule, and Federal Hazardous Substance Laws, Concerning the Performance of the Environmental Protection Agency in the Matter of the Texas Eastern Gas Pipeline Company. Washington, DC: US Government Printing Office. 
Boudia et al.

Engaging Science, Technology, and Society 4 (2018)

Vogel, Sarah A. 2013. Is it Safe? BPA and the Struggle to Define the Safety of Chemicals. Berkeley: University of California Press.

Warren, Christian. 2000. Brush with Death: A Social History of Lead Poisoning. Baltimore, MD: Johns Hopkins University Press. 